\title{
Managerial Decisions on International Price Adaptation: An Abstract
}

\author{
Christina Papadopoulou, Aristeidis Theotokis, and Magnus Hultman
}

\begin{abstract}
The study investigates how international pricing decisions are made. Specifically, how and under what conditions psychic distance affects managers' export pricing adaptation/standardization decisions. Based on construal-level theory, we develop a model that suggests managerial promotion orientation and firm culture as the boundary conditions and construal-level mindset as the underlying mechanism of the psychic distance-price adaptation decision. Using a scenariobased experiment, with export managers in Greece and Taiwan, we find that psychic distance has a significant positive effect on price adaptation, but this effect is becoming nonsignificant for firms located in Asia. Moreover, for firms located in Europe, the positive effect of psychic distance becomes weaker when managers are characterized by higher promotion orientation. Results also confirm that construal-level mindset mediates the perceived psychic distance effect on price adaptation decisions. The article contributes in the export marketing literature by uncovering boundary conditions and an underlying mechanism for the effects of psychic distance and provides value-adding managerial implications.
\end{abstract}

References Available Upon Request

C. Papadopoulou $\bullet$ A. Theotokis $\bullet$ M. Hultman $(\bowtie)$

University of Leeds, Leeds, UK

e-mail: bn14cp@leeds.ac.uk; a.theotokis@leeds.ac.uk; m.hultman@leeds.ac.uk 